\title{
BIENALSUR. La reinvención del concepto de BIENAL desde América del Sur
}

DOI: http://dx.doi.org/10.25087/resur3a5

BIENALSUR es algo así como el acrónimo de la lera Bienal Internacional de Arte Contemporáneo de América del Sur. Ver: http://bienalsur.org/es/bienalsur

BIENALSUR es una creación universitaria innovadora, sustentada por la Universidad Nacional de Tres de Febrero (UNTREF) de la República Argentina, importante universidad pública localizada en el Conurbano bonaerense, en Caseros, y en la Ciudad Autónoma de Buenos Aires para sus cursos de posgrado.

La responsabilidad por BIENALSUR recae en el Rector de UNTREF, Director General del Bienal, y en Diana Wechsler, su Directora Artístico-académica.

En desarrollo durante el 2016 y a lo largo del 2017, tomando como espacio de exhibición el territorio sudamericano y haciendo foco en el proceso de creación artístico e intelectual, BIENALSUR concentrará sus exhibiciones entre septiembre y diciembre de 2017.

Organizada por la tiene a su rector Aníbal Jozami como Director General y a Diana Wechsler como la Directora Artístico-académica.

BIENALSUR funciona como un mecanismo de integración guiado por una lúcida percepción sociológica: en un continente que es desde hace tiempo un espacio fuertemente urbanizado, el arte contemporáneo no puede estar ajeno a esa experiencia urbana, a la vez multicéntrica y simultánea. BIENALSUR involucra a más de 30 ciudades en 15 países y reúne a 250 artistas y del mundo global.

Así, las exposiciones se desarrollan en diversos centros culturales y museos, o en espacios públicos significativos. Según la definen sus impulsores, se trata de una: "red global de colaboración asociativa institucional que elimine distancias y fronteras, y reivindique la singularidad en la diversidad; BIENALSUR propone un extenso territorio construido a partir del posicionamiento en un "Sur Global". 


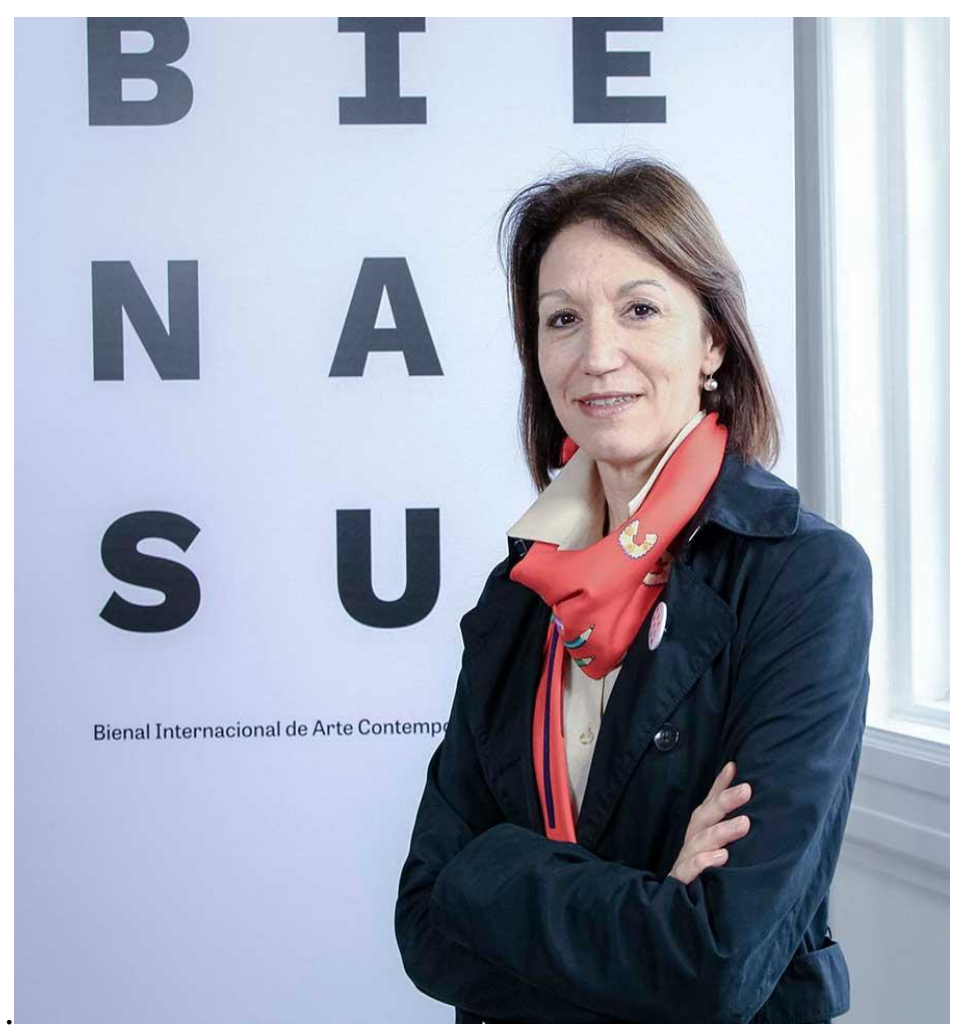

Curadora argentina. Es Doctora en Historia del Arte e investigadora del CONICET. Directora del Instituto de Investigaciones en arte y cultura "Dr. Norberto Griffa" y de la Maestría en Curaduría en Artes Visuales de la Universidad Nacional de Tres de Febrero. En la misma Universidad, es subdirectora de los Museos. Es también profesora titular de Artes Argentino en la UBA. Ha recibido becas y subsidios, entre otros, el Posdoctoral Fellowship de la Gey Foundation. Obtuvo los premios a la Curaduría y Ensayo de Arte de la Asociación Internacional de Críticos de Arte y de Producción Científica de la Cámara de Senadores de la República Argentina.

Las obras han sido seleccionadas en un riguroso e intenso proceso, sobre miles de propuestas provenientes de decenas de países. La "presencia recurrente de proyectos que dialogan fuertemente tanto dentro como fuera del mundo del arte" contribuyó a gestar el perfil de BIENALSUR, que se constituyó en un formato inédito de funcionamiento: "por el cual el arte de cada región no se integre como mera cuota de diversidad, sino que funcione con respeto por las singularidades, redefiniendo los posicionamientos tradicionales, complejizando las relaciones, recuperando tradiciones, estableciendo otros lazos entre espacios y tiempos, siendo congruentes". 


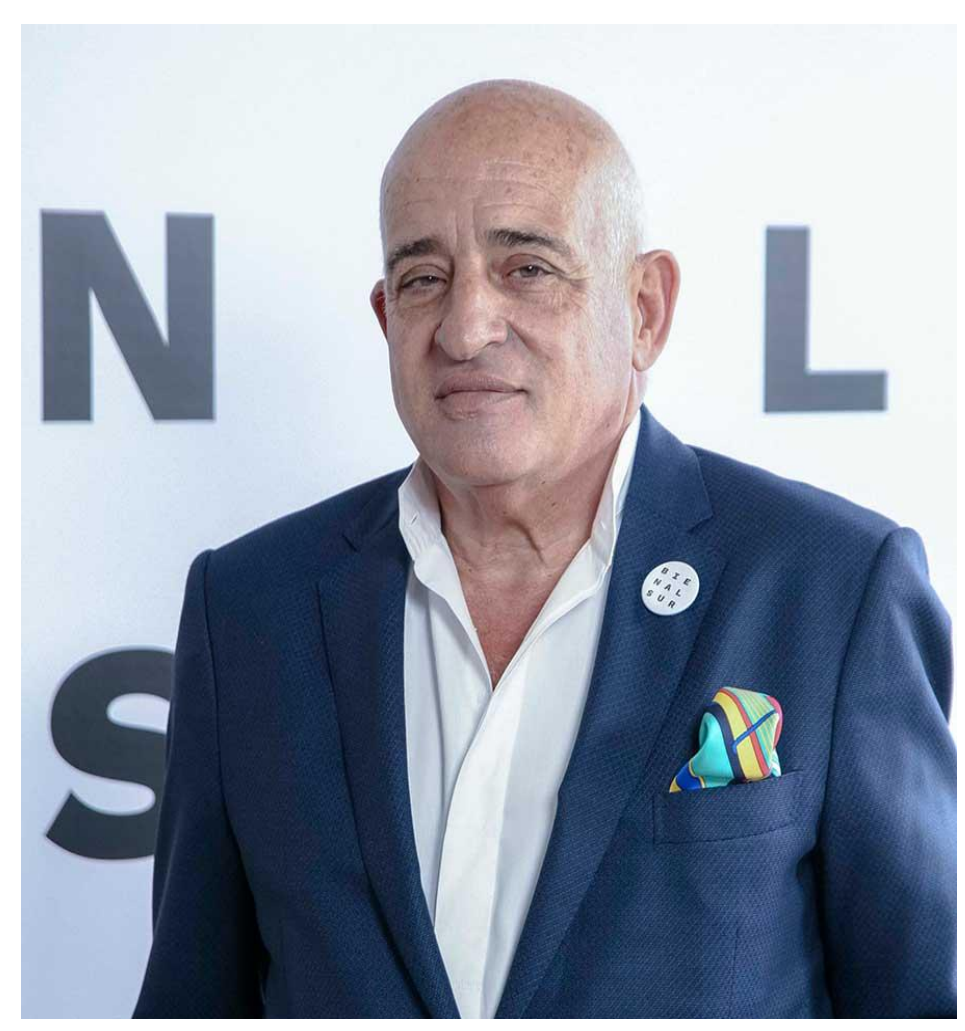

Sociólogo especializado en Relaciones Internacionales, empresario y coleccionista de arte. Es rector de la Universidad Nacional de Tres de Febrero, asimismo dirige los Museos de la Universidad. En 1993, creó la Fundación Foro del Sur, organización no gubernamental destinada a reunir dirigentes políticos, empresarios y académicos con el propósito de generar políticas de Estado en el ámbito de Sudamérica. En 2015 fue electo por los ministros de cultura de los países sudamericanos para proyectar, organizar y dirigir la Bienal Internacional de Arte Contemporáneo de América del Sur, BIENALSUR.

La Bienal internacional de Arte Contemporáneo de América del Sur, sale del molde tradicional de la Curaduría, redefiniendo las reglas convencionales del oficio, mientras contribuye a una alta visibilidad de América del Sur y del Sur Global en la cartografía del arte contemporáneo

Su metodología asociativa ha estimulado la conformación de una verdadera red de cooperación universitaria que integran diversas instituciones de América Latina -entre ellas IUSUR. 
Cinco líneas de trabajo definen el abordaje de BIENALSUR: Acciones e interferencias en el Espacio Público; Curadurías BIENALSUR (muestras en salas) de obra; Colección de colecciones; Proyectos Asociados; Arte en las Fronteras

Desde el MUNTREF, ubicado en el antiguo Hotel de Inmigrantes en el puerto de Buenos Aires, se despliega la cartografía de BIENALSUR, un orden geográfico, cultural y simbólico, cargado de significación contemporánea, conectado, asociativo, multicultural, poli-céntrico, reflexivo, fronterizo, abierto a la diversidad, integrador del arte y de la vida, y los espacios públicos con los de la creación subjetiva, concebido desde el Sur Global, un nuevo modelo de bienal, emergente, humanista y sostenido desde espacios universitarios.

De septiembre a diciembre de 2017 la agenda completa de BIENALSUR podrá consultarse en www.bienalsur.org. 


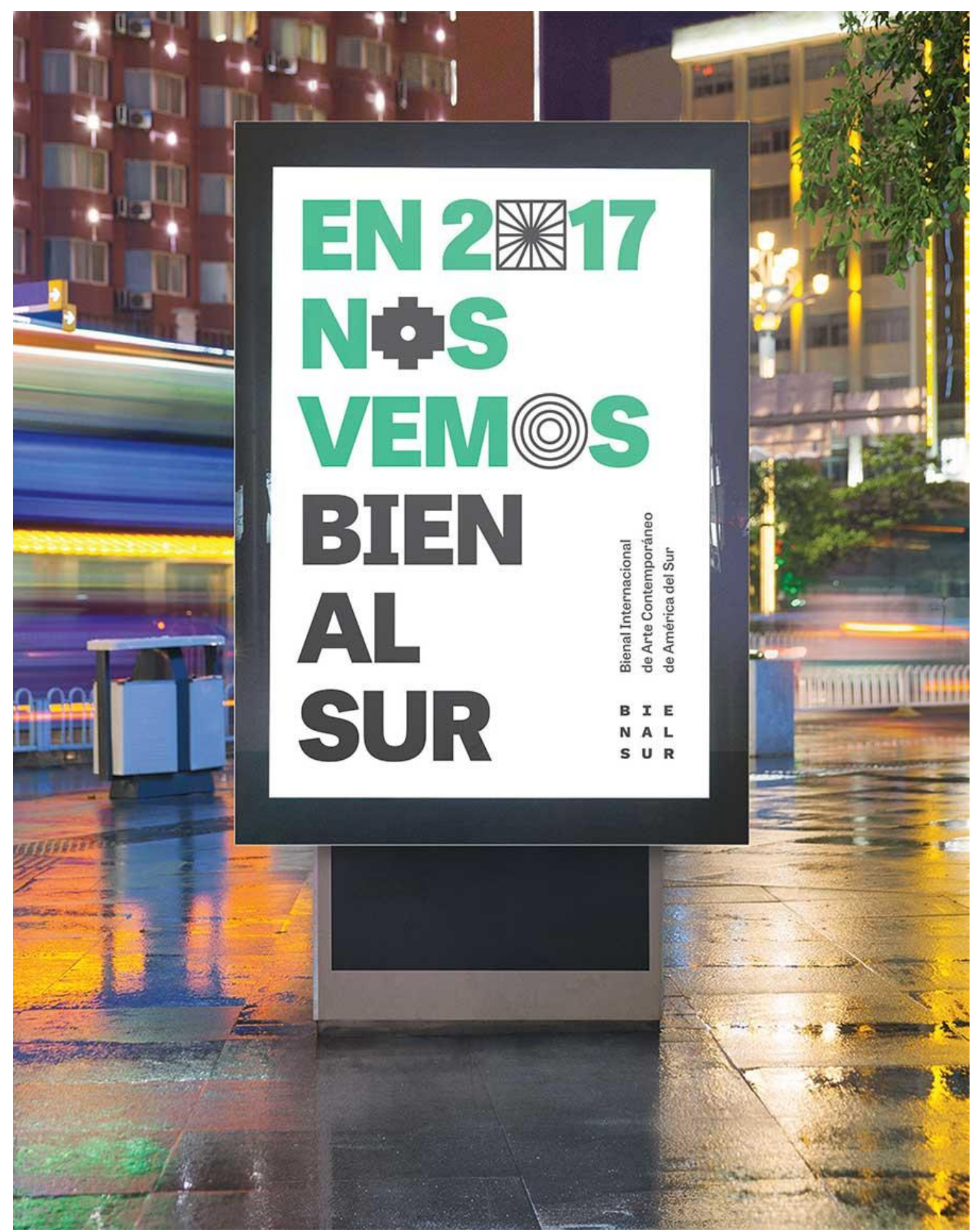

